\title{
The anatomical basis of prosopagnosia
}

\author{
J. C. MEADOWS ${ }^{1}$ \\ From the Aphasia Unit, Boston V.A. Hospital, Boston, U.S.A., \\ and National Hospital, Queen Square, London
}

SYNOPSIS Evidence is presented that patients with prosopagnosia have right anterior inferior occipital lesions in the region of the occipital temporal junction. Many if not all cases have an additional lesion in the left hemisphere; this is often but apparently not always symmetrical with the right hemisphere lesion. This evidence is discussed in relation to the anatomical connections of these regions and the results of experiments in animals.

Prosopagnosia is the specific inability to recognize familiar faces. Its clinical features have been well reviewed by previous authors-for example, Hécaen and Angelergues (1962). It will be pointed out here only that the severely prosopagnosic patient typically has no difficulty recognizing everyday objects, although he may be quite unable to recognize even members of his family unless they speak, when he immediately recognizes their voices. Some severely prosopagnosic patients may recognize certain people by utilizing some specific attribute, such as a mole on the face, unusual height, spectacles of particular design, individual clothes, etc. However these features can be described in verbal terms, and the visual percept of faces without such features does not lead to recognition.

Patients with this rare symptom have posteriorly placed cerebral lesions with physical signs suggesting bilateral involvement in some cases but in others there is clinical evidence only of right hemisphere disease. Visual field defects are nearly always present, but these are not sufficient to account for the prosopagnosia, for other visual material is usually perceived normally. Unfortunately, pathological studies have been few and have not led previous authors to any firm conclusions on the anatomical lesions involved. Rondot and Tzavaras (1969), who have reviewed the subject extensively, mostly from the neuropsychological point of view, have

1 Present address: The National Hospital, Queen Square, London WCIN 3BG. recently drawn attention to the occurrence of bilateral lesions in published cases that have come to necropsy, although they did not consider in detail the possible significance of the location of these lesions.

In the present author's view, there is already good evidence concerning the localization of lesions in prosopagnosia. This conclusion is based upon an analysis of clinical case reports and a re-evaluation of pathological findings in reported cases. It is the purpose of this paper to marshal this evidence and discuss possible underlying mechanisms.

\section{NEUROPSYCHOLOGICAL ASPECTS}

The possible significance of the anatomical lesions to be described will be better understood if consideration is first given to the normal process of facial recognition and then to the neuropsychological features of prosopagnosia.

FACES AS A CATEGORY It should be realized that recognition of faces is a most complex and sophisticated visual achievement which is particularly gestalt-like in nature, for most faces are resistant to verbal interpretation. We can each probably recognize more than 1,000 faces, the majority of which differ in fine detail, but we do this in a manner which it is quite impossible to convey verbally. It depends on learning what are essentially visual pattern discriminations of great complexity. 
There is no obvious counterpart to facial recognition in other visual experience. Thus, there is no other visual category within which we are required to distinguish and remember such minor differences in detail by predominantly non-verbalizable means. It can be argued that certain individuals have special experience with particular categories (the forester with trees, the horticulturalist with flowers, etc.) and in this respect it is interesting that Bornstein (1963) described a birdwatcher with prosopagnosia who could no longer differentiate similar birds and a prosopagnosic farmer (Bornstein et al., 1969) who could no longer identify his individual cows. These however are special cases. Nevertheless, the prosopagnosic patient of DeRenzi et al. (1968) had difficulty in distinguishing fruit (an apple from a peach) and there have been some cases with inability to distinguish particular chairs (Faust, 1955) or buildings (Pallis, 1955; Beyn and Knyazeva, 1962; Cole and Perez Cruet, 1964). These are less striking than the prosopagnosia possibly because they are less difficult visual tasks and also because they are less purely visual (since it is easier to describe the differences in verbal terms than with faces).

Cases such as those just mentioned are relevant to the question of whether there are special characteristics (apart from the complexity of the task) about the brain's ability to distinguish faces. Certain experimental observations suggest that the brain processes information about faces in a different way from other visual material (see for example, Yin, 1970). This is borne out by the everyday observation that we are strikingly better at recognizing a face as familiar after a single encounter than we are other material-for example, an individual horse or a tree. However, this does not mean that skill in perception of faces is a fundamental and primitive capacity of the brain, as has been argued by some authorsfor example, Bodamer (1947). It may be that we learn to distinguish faces to a degree not seen with other categories because facial recognition is from the very earliest age and throughout life such an essential and determining aspect of daily living. Thus, it can be argued that we might have acquired the same perceptual skill in relation to the configuration of one tree relative to the next, if tree configuration were as major a determinant of behaviour as is faces. The farmer and bird watcher mentioned in the last paragraph who had acquired skills with other categories, and subsequently lost them when they developed prosopagnosia, would tend to support this 'acquired' view, as does the wellknown observation that 'all Chinamen look alike' to the untravelled Westerner, but not to the Westerner who has spent years in the Orient.

The cautious conclusion is thus reached that there are special characteristics about the brain's ability to discriminate and remember faces but these may be acquired rather than inborn. The same skills may not be acquired with other categories simply because there is no cultural pressure to acquire them. Accordingly, facial recognition becomes by far the most complex and frequently encountered example of relatively pure visual discrimination learning that occurs in everyday life. Considered in this way it becomes less surprising that it may be disturbed in relative isolation.

PROSOPAGNOSIA AND THE AMNESIC SYNDROM Perhaps the most important recent discovery in relation to prosopagnosia is that patients witho this condition, who are unable to recognize familiar faces, perhaps even those of close friends and family, may be able to discriminate and match faces normally. In other words the disturbance appears to be one of memory for faces. To understand this better, it is helpful to consider some of the ways in which facial recognition has been studied, together with the results that have been obtained.

A considerable literature has built up in recent years showing that the right cerebral hemisphere plays a special role in visual perception and visual memory, and indeed patients with right hemisphere lesions who are not suffering from clinical prosopagnosia perform less well than those with left hemisphere lesions on scored tests involving facial discrimination (DeRenzi and Spinnler, 1966; Warrington and James, 1967; Benton and Van Allen, 1968; Tzavaras et al., 1970). Such tests have been of three broad types:

1. Those testing visual memory for faces-such as recognition of photographs of well-known public figures (Warrington and James, 1967), or 
of previously unknown faces after an appropriate delay (Milner, 1968). This type of test is the most closely related to the clinical symptom of prosopagnosia and was shown statistically by these authors in unselected series of patients to be most impaired in right temporal lesions. (In none of these patients was clinical prosopagnosia present.)

2. Those testing immediate recall of previously unfamiliar faces (DeRenzi and Spinnler, 1966; Warrington and James, 1967; Milner, 1968). The subject might be shown a facial photograph which is then removed, and he is then immediately told to pick out the face from a display of several faces.

3. Various matching tasks, in which a facial photograph is matched with other photographs of the same face (Benton and Van Allen, 1968; Tzavaras et al., 1970). In some tests, matching has been with photographs taken from different angles or in different ambient lighting, or modified by grimaces, false beards, spectacles, etc.

While performance in all these tests is impaired statistically in unselected groups of patients with right hemisphere lesions, they are not necessarily impaired to the same extent. Thus, Warrington and James (1967) found no correlation in their series of patients (none of whom was clinically prosopagnosic) between impaired recognition of well-known faces and impaired immediate recall of unfamiliar faces. They speculated that prosopagnosia might be a localized form of the amnesic syndrome (a point previously hinted at by Hécaen et al., 1957). The amnesic syndrome is characterized by impairment of memory (both verbal and visuospatial) with preservation of adequate intellectual functions, and results from bilateral damage to central core limbic structures (see, for example, Brierley, 1966). Amnesic patients certainly perform poorly in recognizing well-known faces (as they do in other tests of memory) and they are typically unaffected in matching tasks and in immediate recall of faces.

This notion would hold, therefore, that prosopagnosia is a disturbance of one aspect of visuospatial memory. Some support for this view comes from Milner's (1968) finding that delayed recognition of faces was impaired (though not to the extent seen in prosopagnosia) after right temporal lobectomy, while immediate recall was not, and from subsequent reports that patients with true prosopagnosia may perform normally on matching tasks. This has been so in three patients so far reported (Tzavaras et al., 1970; Benton and Van Allen, 1972). However a fourth patient reported by DeRenzi et al. (1968) performed badly on matching tasks and on both immediate and delayed recall, indicating that a restricted form of amnesia cannot account for all cases.

There are objections to considering prosopagnosia as a restricted form of the amnesic syndrome. If this were so, one would expect amnesic patients-for example, patients with alcoholic Korsakoff's psychosis-also to be prosopagnosic. In fact, it is very unusual for the difficulty in recognizing faces that is experienced by amnesic patients to compare in severity with true prosopagnosia. The severely amnesic patient is certainly unable to learn new faces but the author is aware of no convincing case where this difficulty extended retrogradely to faces learnt in the remote past, as in prosopagnosia. The severest degree of deficit is exemplified by the much studied subject H.M., who was amnesic after bimedial temporal lobectomy. This subject has for many years since operation had severe difficulty in facial recognition, being unable even to recognize friends and neighbours (first met after operation) who have been visiting him regularly for years (Milner, 1966). He has even been known to invite total strangers into the house to await his mother's return, thinking that they must be friends he has not recognized. By contrast, the reports indicate that he recognizes his parents normally. Such preservation of remote memory is a regular feature of the amnesic syndrome which seems to be absent in prosopagnosia. Thus, the disturbance of memory for faces in prosopagnosia appears to be more severe and different in character from that produced by bilateral lesions of central core limbic structures.

It is interesting to note, however, that patients with prosopagnosia very frequently have disturbance of another memory function-topographical memory (Hécaen et al., 1957; Bornstein, 1963; Rondot and Tzavaras, 1969). This is of some relevance, since patients with the amnesic syndrome itself have obvious clinical difficulty in two major visual functions-topographical orientation and facial recognition. In 
fact, topographical orientation (memory) is less purely visual than is facial recognition, since in general it involves more verbalizable material. Nevertheless, this relationship provides additional support for those trying to relate prosopagnosia and amnesia, in spite of the objections that have already been voiced.

There is some evidence that topographical orientation and facial discrimination may be dissociable at cortical level: Newcombe and Russell's (1969) study of missile-injured patients showed that a maze-learning task was more impaired with right parietal lesions, while defects of facial discrimination (Mooney's closure test) were most severe in patients with right temporal lesions. We can therefore speculate on whether prosopagnosia might depend upon some lesion intermediate between a posterior area required for facial discrimination and more anterior temporal structures (with possible limbic connections) required for learning. Such a lesion might also interrupt similar connections concerned with topographical memory. The anatomical evidence to be presented is compatible with this hypothesis.

\section{THE ANATOMICAL EVIDENCE}

In the majority of published cases of prosopagnosia exact localization of the lesions is not described. Investigations have been scanty and analysis of the reported clinical details is frequently unrewarding from the viewpoint of precise localization. It is clear that in many cases there is evidence of bilateral disease (shown usually by bilateral field defects), although in some there is evidence only of right hemisphere involvement. Whether the overall clinical picture suggests unilateral or bilateral disease, however, there is one clinical feature which is of good localizing value. A left upper quadrantic visual field defect is a remarkably consistent finding in reported cases. In a few cases, radiological or operative findings have been described and in a small number there have been necropsies. However, to the author's knowledge, there are only seven detailed reports of necropsies in the literature (but see Addendum).

VISUAL FIELD DEFECTS The visual field defects in a large series of patients with prosopagnosia are shown in Fig. 1. These comprise all reports known to the author which have been published during the last 40 years, together with five cases from the records of the National Hospital, Queen Square and Maida Vale. The cases briefly mentioned in Bornstein's review (1963) are not included because of inadequate neurological details.

The present cases (1-5) will not be reported in detail in this paper. Case 1 had a large posteriorly placed right hemisphere glioma with radiological evidence of invasion of the corpus callosum. Cases 2, 3, and 5 had each had two or more strokes with historical evidence of involvement of both hemispheres. Case 4 , a previously healthy 33 year old man, developed prosopagnosia after evacuation of a right posterior temporal haematoma, arising from a minute angiomatous malformation. In this case, the prosopagnosia was not as severe as in the other cases; he could, for example, recognize his wife without difficulty, but failed to recognize people that he met only once or twice a year (such as his cousins and certain close friends) even though he had known them for many years. In all these cases there was evidence of impaired topographical orientation.

Several points emerge from examination of Fig. 1 . Visual field defects are nearly always present, and bilateral defects occur in about half the cases. However, in the unilateral cases, the defect is nearly always on the left. Most notable of all is the frequency of left upper quadrant involvement, suggesting a low, posteriorly placed lesion of the right cerebral hemisphere. Thus left upper quadrant involvement was noted in all the 19 cases with unilateral left-sided defects and in all but one of the 15 cases with bilateral defects. There were however four cases with unilateral right-sided defects and four cases without visual field defects. It is worth noting at this point that two of the four cases with unilateral right-sided defects subsequently died and at necropsy had discrete right occipitotemporal pathology in addition to lesions in the left hemisphere (Arseni and Botez, 1958; Benson et al., 1974).

Of the cases without field defects, two resulted from carbon monoxide poisoning (Hécaen et al., 1957; Benton and Van Allen, 1972), while a third (Macrae and Trolle, 1956) followed closed head trauma with coma for three weeks-conditions which usually cause bilateral brain damage. Bilateral damage in the case of Macrae 
Milian (1932)

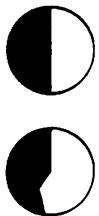

Hécaen et al. (1952) case 2

Klein and Stack (1953)

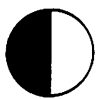

Alajouanine et al. (1953)

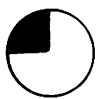

Faust (1955)—case 1

Faust (1955) - case 2

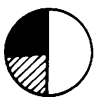

de Busscher et al. (1956)

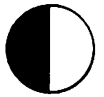

Hécaen et al. (1956) case 1

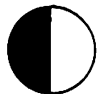

Hécaen et al. (1956) case 2

Hécaen et al. (1957) case 2

Bornstein and Kidron (1959)

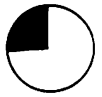

Gloning et al. (1966) case 1

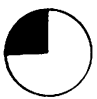

De Renzi et al. (1968)

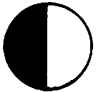

Bornstein et al. (1969)

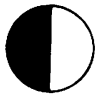

Assal (1969)

Assal (1969)

FIG. 1. Visual field defects in cases of prosopagnosia published since 1930, including those of five cases from the records of the National Hospital, Queen Square. The defects were homonymous but for convenience are here represented by a single field. The cases have been arranged into four groups depending upon whether there were left-sided defects alone, bilateral defects, right-sided defects alone, or no defects.
Cole and Perez Cruet

(1964)

Gloning et al. (1966) case 2

Rondot et al. (1967)

Gloning et al. (1970)

Meadows (1973)—case 5

Potzl (1953)

Arseni and Botez (1958)

Faust (1955)—case 4

Rubens and Benson (1971)
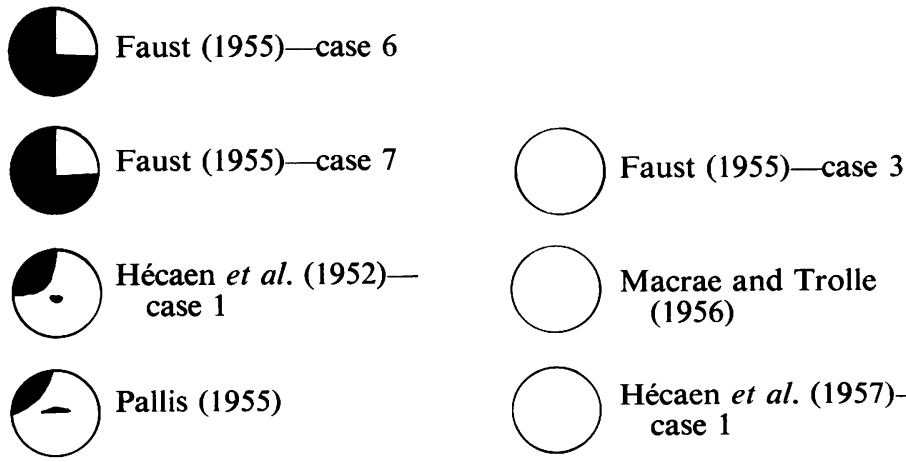

Pallis (1955)

Hécaen et al. (1957) case 1
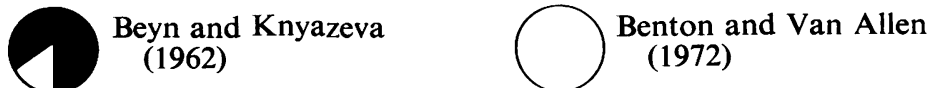
and Trolle was supported by the finding of tachistoscopic tunnel vision for depth and colour. Carbon monoxide poisoning in particular may damage visual association cortex bilaterally and cause cortical visual impairment (Garland and Pearce, 1967) or visual agnosia (Benson and Greenberg, 1969). The author knows of an additional case of carbon monoxide induced prosopagnosia without visual field defect in whom less troublesome visual agnosia was also present (M. Espir, personal communication).

The fourth published case without visual field defect (Faust, 1955) had clear evidence of right occipitotemporal damage, even though no field defect was recorded. In this case, which resulted from a missile injury, there was a right occipitobasal bone defect associated with a piece of metal $3 \mathrm{~cm}$ from the midline close to the petrous temporal bone, with dilatation of the trigone and posterior horn of the right lateral ventricle on contrast radiography.

NECROPSY LOCALIZATION Pathological studies confirm the presence of right occipitotemporal pathology in all cases so far published and in most cases there was an approximately symmetrical lesion in the left hemisphere. In all cases there was evidence of bilateral disease (Table). In Wilbrand's case (1892) there was right occipital softening extending inferiorly from the calcarine fissure, with a corresponding

TABLE

LOCATION OF LESIONS IN CASES OF PROSOPAGNOSIA THAT CAME TO NECROPSY

\begin{tabular}{|c|c|c|}
\hline & Right hemisphere & Left hemisphere \\
\hline \multirow{3}{*}{$\begin{array}{l}\text { Wilbrand } \\
(1892) \\
\text { Heidenhain } \\
\quad(1927) \\
\text { Hécaen et al. } \\
(1957)\end{array}$} & Inferior occipital & Inferior occipitotemporal \\
\hline & Inferior occipitotemporal & Inferior occipitotemporal \\
\hline & Occipito-parietotemporal & $\begin{array}{l}\text { Invasion through } \\
\text { splenium to } \\
\text { ventricular wall }\end{array}$ \\
\hline $\begin{array}{l}\text { Arseni and } \\
\text { Botez (1958) } \\
\text { Pevsner et al. }\end{array}$ & Occipito-parietotemporal & Occipitotemporal \\
\hline $\begin{array}{l}\text { (1962) } \\
\text { Gloning et al. }\end{array}$ & Inferior occipitotemporal & Angular gyrus region \\
\hline (1970) & Inferior occipitotemporal & Inferior occipitotemporal \\
\hline$(1974)$ & Inferior occipitotemporal & Inferior occipitotemporal \\
\hline
\end{tabular}

small area of softening in the left hemisphere. Heidenhain's case (1927) showed infarction inferiorly, in the region of both occipitotemporal junctions, involving fusiform and lingual gyri. The case of Hécaen et al. (1957) had a rightsided glioblastoma which at operation was invading the occipital lobe, the posterior parts of the parietal and temporal lobes, and also the posterior part of the corpus callosum. Eventually the patient died and necropsy confirmed the presence of a glioma which by now was infiltrating extensively throughout the right temporal and occipital regions. Involvement was however maximal in the medial and inferior aspects of the occipital and posterior temporal regions, with extension into the corpus callosum as far as the opposite ventricular wall.

The case of Arseni and Botez (1958) was of a bipolar spongioblastoma which at necropsy was infiltrating extensively the left occipitotemporal region. There was an additional deposit, about $1.5 \mathrm{~cm}$ in diameter, described as involving the region of the tapetum on the right.

The case of Pevsner et al. (1962), reported in life by Bornstein and Kidron (1959) showed the following findings at necropsy:

'In the middle of the left inferior parietal lobule, inco the angular gyrus and in the upper part of the? superior temporal sulcus, a yellow-brown, slightly depressed lesion, $3 \mathrm{~cm}$ in diameter was found. The anterior border of this lesion was formed by the angular gyrus and it extended on to the parietooccipital sulcus which also formed its posterior border. These macroscopic findings at autopsy extended to a depth of $1 \mathrm{~mm}$. On microscopy signs of mild atrophy, gliosis and rarefaction of cells was seen.... On section of the brain, a narrow cystic cavity, $1 \mathrm{~cm}$ in length ... was found in the region of the inferior border of the medial surface of the right hemisphere, $3 \mathrm{~cm}$ anterior to the occipital pole, under the calcarine fissure which also formed the roof of the lesion. It was 4-6 mm below the cortex.'

The patient of Gloning et al. (1970) sustained a series of cerebrovascular accidents in the few months before death and at necropsy there were areas of softening in various parts of the brain. Most striking in relation to his long-standing symptom of prosopagnosia, however, were old, bilateral ischaemic infarcts, situated almost symmetrically in the region of the occipitotemporal junction, destroying the central parts 
of both fusiform gyri. They extended deeply and involved the basal parts of the optic radiations but spared the striate cortex.

Finally, the patient with associative visual agnosia reported in life by Rubens and Benson (1971) has recently died. This patient had severe prosopagnosia which persisted after ability to name common objects on visual presentation had become almost flawless. Necropsy in this patient (Benson et al., 1974) showed infarction in left posterior cerebral artery distribution with splenial destruction and a second, discrete lesion involving the right fusiform gyrus. The latter involved predominantly the white matter, extending from a point about $2 \mathrm{~cm}$ in front of the occipital lobe tip posteriorly to a point about $1.5 \mathrm{~cm}$ anterior to the junction of parieto-occipital sulcus with calcarine sulcus.

These are the only well-described necropsy reports but there are two other cases that came to necropsy mentioned briefly in the literature, both reported by Bornstein $(1963,1965)$. His first case is confusing; in the case report the lesion is described as a right occipital lobe meningioma causing left-sided hemianopia, yet later in the paper he refers to the 'meningioma in the left parieto-occipital lobe'. Necropsy is not mentioned in this paper. In his second publication he refers again to this case and also mentions an additional case. Without giving further details he states simply that postmortem examination 'revealed a left parieto-occipital meningioma in one case and a glioblastoma in the same region in the second'. It is difficult to comment on either of these cases without further details.
RADIOLOGICAL OR OPERATIVE LOCALIZATION There are a few cases in which approximate localization can be deduced from radiological and operative findings. In these cases the findings are in keeping with those already described. Hécaen and Angelergues (1962) mention three cases with difficulty in facial recognition after surgery to the posterior part of the right cerebral hemisphere: removal of right parieto-occipitotemporal region and right occipitotemporal region in two cases with intractable epilepsy, and removal of a large right parieto-occipital meningioma in the third. The case of Pallis (1955) showed defective filling of the right posterior cerebral artery on angiography but there were bilateral visual field defects indicating bilateral involvement. Assal (1969) described a patient with a proven right parietotemporal intracerebral haemorrhage, and haemorrhage in the right posterior temporal region was responsible in the present case 4 . Finally, the present case 1 had a large deeply placed glioma in the posterior part of the right hemisphere. Its localization is most easily seen from the brain scan (Fig. 2). Carotid and vertebral angiograms indicated a large malignant tumour lying deep in the right, posterior temporoparietal region and involving the splenium of the corpus callosum. At operation, a large tumour was encountered at a depth of $2 \cdot 5$ $\mathrm{cm}$ from the surface convexity of the brain. Further exploration showed that it had come through the medial surface of the hemisphere and was extending under the free edge of the falx in the region of the vein of Galen. It also occupied the body of the right lateral ventricle, bulging into it

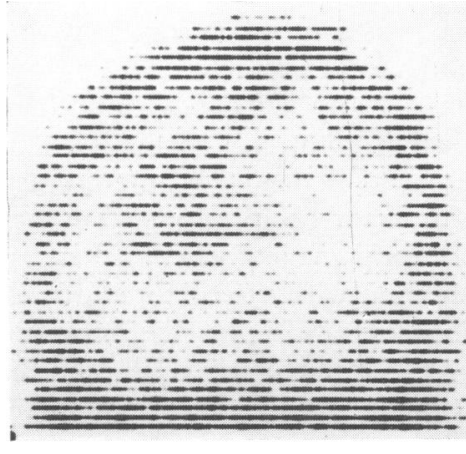

(a)

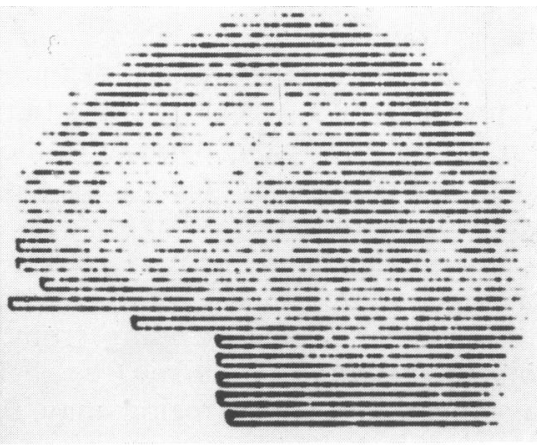

(b)
FIG. 2. Technetium brain scan of the present case 2 , (a) anteroposterior and (b) right lateral views. 
from its medial side. An incomplete removal was performed. The patient was not followed up.

\section{DISCUSSION}

LOCATION OF LESIONS The evidence that has been presented points clearly to the importance of occipitotemporal lesions in prosopagnosia. The evidence for right-sided involvement is very strong: lesions in this region were found in all the seven cases that came to necropsy so far reported, and this correlates with the extremely high incidence of left upper quadrantic visual field defects in clinical case reports. On the other hand, lesions at this site in the left hemisphere were found in only five of the seven necropsies, and right upper quadrantic field defects are not particularly common clinically.

The lesions in the right hemispheres involved fusiform or lingual gyri in six of the seven cases. Immediately deep to these gyri lies the optic radiation, and this structure was obviously involved in most if not all these cases (a clear statement is not made in every case). In the seventh case (Arseni and Botez, 1958) the lesion was more dorsally placed, and was described as involving the tapetum (callosal fibres sweeping down into the occipito-temporal region).

Left hemisphere lesions were present in all seven necropsies but only in five were these occipitotemporal as in the right hemisphere (Table). In the case of Pevzner et al. (1962) that came to necropsy the only left-sided lesion described was mild gliosis in the angular gyrus region. In the case of Hécaen et al. (1957) there was invasion by tumour from the right hemisphere through the posterior part of the corpus callosum, but only as far as the ventricular wall. As already stated, the purely clinical data also fail to support the consistent presence of symmetrical lesions, for right upper quadrantic field defects are not a regular finding in published case reports; in about half the cases there is no right field defect at all and in some of the cases where a right-sided defect is present it spares the right upper quadrant (Fig. 1). We may conclude rather cautiously at this point that bilateral occipitotemporal lesions may underlie many cases of prosopagnosia but that in some (and possibly many) cases, the right occipitotemporal lesion is not accompanied by a correspondingly sited lesion in the left hemisphere.

What is the mechanism of the disturbance produced by these occipitotemporal lesions? Their gross location has been discussed, but the possible pathways affected have not yet been considered. For the present, we will leave aside the question of whether the lesion at this site is unilateral or bilateral and just consider the possible structures involved.

The lesions that have been described affect mainly inferior occipitotemporal cortex (lingual and fusiform gyri) and do not usually extend forward far into the temporal lobe. They also involve the white matter deep to these gyri, comprising incoming and outgoing fibres to this cortex (including tapetal fibres descending from the posterior part of corpus callosum), inferior longitudinal fasciculus (ILF) and lower fibres of optic radiation.

In fact, the lower part of the optic radiation fuses and is intermingled with ILF, which is the main pathway from the classical visual association cortex (areas 18 and 19) into the temporal lobe. These two structures are together known as the external sagittal stratum. A lesion of the lower part of the right optic radiation in the occipitotemporal region (accounting for the left upper quadrantic field defect) will thus almost certainly involve ILF and is likely in addition to interrupt callosal (tapetal) connections between inferiorly placed occipitotemporal cortex on the two sides. Even the more dorsally placed lesion in the case of Arseni and Botez (1958) probably involved the external sagittal stratum, for this structure is closely applied to the tapetum, upon which the tumour was centred, just lateral to the ventricle.

These basal occipitotemporal lesions may thus interrupt the main visual input to the temporal lobe in addition to any effects arising from damage to the occipitotemporal cortex itself. In fact, some fibres of ILF probably interconnect various parts of inferior occipital and temporal cortex, and ILF may even form a chain of connections concerned with visual function, extending from the occipital into the temporal lobe (see below). Damage to ILF in this region may thus have some effects similar to lesions of occipitotemporal cortex itself, by involving the latter's incoming and outgoing con- 
nections. Damage to the long fibres in ILF is probably not important, for prosopagnosia does not appear to be associated with lesions more anteriorly in the temporal lobe, further along the course of these same fibres.

COMPARISON WITH ANIMAL EXPERIMENTS Some insight into the possible neuropsychological mechanism of lesions at this site may be gained by considering the results of experiments in animals. Prosopagnosia associated with bilateral occipitotemporal lesions might be compared with the defect of visual discrimination learning (with sparing of both primary visuosensory function and learning in other modalities) which follows bilateral ablations of inferotemporal cortex in the macaque (see review by Gross, 1974). This analogy may be relevant even to cases with involvement of only the right occipitotemporal region, for this is the side of the brain which, in man, is most concerned with visuospatial function and, more specifically to the present context, with facial discrimination and recall (see the statistical studies on unselected series of brain damaged patients already discussed).

A simple explanation of prosopagnosia can thus be suggested based on the occipitotemporal location of the lesions and the fact that similarly placed lesions in monkeys impair visual discrimination learning. In man, facial recognition is so much more complicated and more frequently undertaken than any other task involving complex visual discrimination learning that part of the inferior occipitotemporal cortex appears to become functionally modified for this task. It is suggested that destruction of this cortex or its connections underlies prosopagnosia. Connections from this region to more anterior temporal cortex and thence to medial limbic structures are apparently still necessary for learning new faces, as has already been discussed in relation to the amnesic syndrome.

THE PROBLEM OF THE LEFT HEMISPHERE LESION SO far we have avoided discussing the difficult problem of the variable location of the left hemisphere lesions and the question that follows from itwhether bilateral lesions are essential or not for the development of prosopagnosia. It has already been noted that bilateral lesions have been present in all cases that came to necropsy but that the lesions in the left hemispheres have not all been occipitotemporal in location. Similarly, the evidence from clinical studies, in particular the visual field data, leads one to question the role of the left hemisphere (at the very least, it must be different from the role of the right hemisphere). This, of course, accords with the statistical studies in unselected brain damaged patients which show that the right hemisphere is of much greater importance in facial discrimination and recall. It is natural to question whether the left hemisphere lesion is necessary at all. The evidence, however, is overwhelming that bilateral lesions are important in the overall aetiology of prosopagnosia. The high incidence of bilateral disease clinically and the invariable presence of bilateral lesions in the few necropsies so far performed can scarcely have occurred by chance. Moreover, bilateral lesions conveniently explain the rarity of the condition. However, this still does not explain the inconsistent location of the left hemisphere lesion. It is not unreasonable to suggest, for example, that the left occipitotemporal lesions are important (being located roughly symmetrically to those in the right hemisphere) but that in the two cases that came to necropsy where the left hemisphere lesions were not occipitotemporal (Hécaen et al., 1957; Pevzner et al., 1962) they might be incidental and irrelevant.

Some alternative possibilities might be considered to account for some of the anomalies that have been discussed-in particular the clinical evidence implicating the right hemisphere more than the left. Some of those patients with clinical evidence of only unilateral disease might indeed have only unilateral lesions and be rare individuals in whom visual function, or at least the function of facial recognition, is unusually lateralized in the right hemisphere, whereas in most individuals bilateral lesions are required to cause prosopagnosia. Thus, some cases might have unilateral (right) occipitotemporal lesions, as in the case of Pevzner et al. (1962), while other cases have bilateral occipitotemporal lesions.

Another possibility is that the combination of lesions in bilateral cases has the same effect, so far as physiological mechanism is concerned, as a single strategically placed right-sided lesion. For example, recognition of familiar faces might 
depend on connections from both occipital cortices to the right occipitotemporal cortex. A lesion causing destruction of the right primary visual cortex in combination with destruction at some point along the pathway from the left striate cortex to the right occipitotemporal region (probably via the left visual association cortex, including the left occipitotemporal region, and callosal fibres passing in the splenium) might then have the same effect as a single right occipitotemporal lesion. Damage to the callosal fibres might be in the splenium itself, or more laterally placed in either right or left hemisphere. It will be recalled that there was gliomatous infiltration of the corpus callosum from the right hemisphere in both the case of Hécaen et al. (1957) that came to necropsy and case 1 of the present author. However, this explanation fails to account for the rarity of prosopagnosia, which would, for example, be expected to occur regularly with right posterior cerebral artery occlusion.

Could the last explanation apply if an isolated right hemisphere lesion were particularly discrete in location? Could, for example, the neuronal networks in the chain of connections beyond a particularly discrete right occipitotemporal lesion still have a decisive effect on the brain's response? In other words, might these networks actively 'inform the brain' that a familiar face is unfamiliar simply because they do not receive the information necessary to identify it? It is known that the left hemisphere can identify faces when disconnected from the right hemisphere (Levy et al., 1972) and this is presumably how facial recognition is achieved, for example, when right occipital and basal temporal lobe is destroyed by right posterior cerebral artery occlusion. But, in a particularly discrete right occipitotemporal lesion of the type envisaged, is it possible that the 'negative' information from the right hemisphere in some manner suppresses the 'positive' information from the left hemisphere and leads to an actual denial of recognition? With a larger right hemisphere lesion, the right hemisphere mechanism would be more deranged and identification by the left hemisphere would take place.

This is an interesting speculation but not one which can at the present time be supported; as already discussed, there is so far no firm evi- dence that a unilateral lesion can cause prosopagnosia. It is to be hoped that further necropsy studies will explain some of the paradoxes concerning lesion location, at least at the gross anatomical level.

VARIETIES OF PROSOPAGNOSIA It has already been pointed out that discrimination of faces may be normal in prosopagnosia and that, at least in some cases, the disorder can be considered to be one of memory for faces. However, it is unlikely that a disturbance of visual memory underlies all cases of prosopagnosia. Thus the patient of DeRenzi et al. (1968) was unable even to discriminate faces, judging from his performance on matching tasks and tests of immediate recall. This is not too surprising, for facial recognition is probably not a single-step process but is likely to involve a series of stages. In fact, different types of abnormality can be predicted. Discrimination of faces might be impaired and the subject be unable to say whether two identical facial photographs are the same or not. At a more complex level, he might succeed in this task but be unable to say whether two faces are the same when photographed from different angles or in different ambient lighting. In turn, these processes of perceptual integration might be intact but the patient be unable to draw on memory function required for recognition. The last-mentioned seems to be the commonest type of defect.

The present study suggests that the anatomical substrate for these functions includes the region of the occipitotemporal junction, particularly on the right. Gross et al. (1972) have provided some evidence in the monkey that the sort of hierarchical perceptual processes demonstrated by Hubel and Wiesel $(1962,1965,1968)$ in the geniculostriate system of the cat and monkey may be extended into the inferotemporal cortex for more complex material, and it is reasonable to consider whether a similar mechanism might occur with complex perceptual processes, like facial recognition, in man. The known lateralization of visuospatial function in man is presumably relevant to the apparent greater importance of the right hemisphere but as already discussed certain questions remain unanswered in relation to this.

Such a hierarchical arrangement could under- 
lie clinical differences between reported cases. Against this background, it is easier to understand cases such as that of DeRenzi et al. (1968) with impaired facial discrimination, and cases associated with metamorphopsia (altered or distorted vision), as discussed by Hécaen and Angelergues (1962), where there is a more primary disturbance of perception. The cases of Bodamer (1947) fall into the latter category and his first patient, for example, complained that faces appeared 'strangely flat; white with dark eyes, as if in one plane, like white oval plates . . . all the same' (see Critchley, 1953). Metamorphopsia may also be very pronounced without actual prosopagnosia, as in Bodamer's third patient who really had a specific metamorphopsia involving faces, rather than prosopagnosia, since the patient could still recognize faces.

Finally, it must be remembered that difficulty in facial recognition may occur as part of less specific neurological disturbances. The question of facial recognition in amnesic subjects has already been considered and it has been pointed out that the defect in recognition here does not appear to extend retrogradely to faces learned in the remote past, but only as far retrogradely as the amnesia itself extends; the difficulty is in learning new faces during the period of retrograde and anterograde amnesia.

Facial recognition may also be impaired in patients with visual agnosias (for example, Benson and Greenberg, 1969; Taylor and Warrington, 1971). In these conditions objects cannot be identified when presented visually and it is therefore not too surprising that faces may not be identified either. In 'apperceptive' visual agnosia there is bilateral disturbance of visual association cortex. On the other hand 'associative' visual agnosia has been interpreted as indicating disconnexion between the visual areas and the posterior speech area (Geschwind, 1965) and can result from lesions confined to the left hemisphere. It is theoretically possible that a lesion confined to the left hemisphere might similarly cause isolated prosopagnosia. This would depend upon whether fibres transmitting information about faces are segregated sufficiently from other visual input to the speech area. Of the four cases of prosopagnosia shown in Fig. 1, where the clinical data suggested confinement of pathology to the left hemisphere, two came to necropsy and in both cases bilateral occipitotemporal lesions were found (see previous section); rather surprisingly the two right hemisphere lesions did not cause detectable left visual field defects. Thus there is no evidence at the present time that prosopagnosia can result from an isolated left hemisphere lesion.

In conclusion, however, it is worth considering the possible combined effects of partial interruption of visual input to speech area together with a right occipitotemporal lesion, for such an explanation could explain the problematical case of Pevzner et al. (1962), that came to necropsy where the only reported lesion in the left hemisphere was mild gliosis in the angular gyrus region.

\section{SUMMARY}

Patients with prosopagnosia nearly always have a left upper quadrantic visual field defect, correlated clinically and pathologically with a right occipitotemporal lesion. The few necropsies all show bilateral lesions but the right hemisphere lesions have all involved the region of the occipitotemporal junction.

The lower part of the optic radiation fuses with the inferior longitudinal fasciculus (ILF) and these two structures lie immediately dorsal to inferior occipitotemporal cortex. ILF is the main direct pathway by which visual information reaches temporal lobe (and thence limbic structures), but along its path its fibres also interconnect the different areas of inferior occipitotemporal and posterior temporal cortex. As lesions far forward in ILF are apparently not associated with prosopagnosia, involvement of inferior occipitotemporal cortex or its incoming and outgoing connections is probably the important factor.

All cases of prosopagnosia that have come to necropsy have also shown lesions in the left hemisphere, mostly occipitotemporal, so that approximately symmetrical lesions were present. But in two out of seven necropsies no left occipitotemporal lesion was described. Right-sided visual field defects have been present in only about half the recorded cases. The problem of the inconsistent location of the left hemisphere lesion has not been resolved but various possibilities have been considered. 
Bilateral lesions of inferior temporal cortex in monkeys impair visual discrimination learning. Facial recognition can in many respects be regarded as an extremely complex learning task in visual discrimination.

\section{ADDENDUM}

Since this paper was written, three further cases have been drawn to the author's attention, in one of which necropsy findings were published. A case is reported in Critchley's (1965) paper on anomalies of colour vision of cerebral origin; this patient had a superior altitudinal hemianopia with prosopagnosia, loss of topographical sense, and impaired colour vision with xanthopsia. Lhermitte et al. (1972) report a case that came to necropsy who, in addition to difficulty with faces was also unable to recognize familiar cars, a feature shown to some extent also by the present case 5 and by the case of Macrae and Trolle (1956). At necropsy, Lhermitte's case showed bilateral lesions of fusiform gyrus with, on the right, involvement also of the adjacent lingual gyrus. Finally, Tzavaras, Merienne, and Masure (personal communication) describe a left-handed patient with a left temporal lesion who presented with prosopagnosia, amnesia, and language difficulty.

My thanks are due to Dr. D. Frank Benson for his comments on this manuscript.

\section{REFERENCES}

Alajouanine, T., Lhermitte, F., and Sabouraud, O. (1953) Agnosie visuelle sans alexie. Revue Neurologique, 89, 158.

Arseni, C., and Botez, M. I. (1958). Consideraciones sobre un caso de agnosia de las fisonomias. Revista Neuropsiquiatria, 21, 583-593.

Assal, G. (1969). Régression des troubles de la reconnaissance des physionomies et de la mémoire topographique chez un malade opéré d'un hématome intracérébral pariétotemporal droit. Revue Neurologique, 121, 184-185.

Benson, D. F., and Greenberg, J. P. (1969). Visual form agnosia. Archives of Neurology (Chic.), 20, 82-89.

Benson, D. F., Segarra, J. M., and Albert, M. L. (1974). Archives of Neurology. (In press.)

Benton, A. L., and Van Allen, M. W. (1968). Impairment in facial recognition in patients with cerebral disease. Cortex, 4, 344-358.

Benton, A. L., and Van Allen, M. W. (1972). Prosopagnosia and facial discrimination. Journal of Neurological Sciences, 15, 167-172.

Beyn, E. S., and Knyazeva, G. R. (1962). The problem of prosopagnosia. Journal of Neurology, Neurosurgery, and Psychiatry, 25, 154-158.

Bodamer, J. (1947). Die Prosop-Agnosie. Archiv für Psychiatrie und Nervenkrankheiten, 179, 6-53.

Bornstein, B. (1963). Prosopagnosia. In Problems of Dynamic Neurology, pp. 283-318. Edited by L. Halpern. Hadassah Medical Organization: Jerusalem.
Bornstein, B. (1965). Prosopagnosia. In 8th International Congress of Neurology, Vienna, 1965. Proceedings, Vol. 3, pp. 157-160. Wiener Medizinischen Akademie: Vienna.

Bornstein, B., and Kidron, D. P. (1959). Prosopagnosia. Journal of Neurology, Neurosurgery, and Psychiatry, 22, 124-131.

Bornstein, B., Sroka, H., and Munitz, H. (1969). Prosopagnosia with animal face agnosia. Cortex, 5, 164-169.

Brierley, J. B. (1966). The neuropathology of amnesic states. In Amnesia, pp. 150-180. Edited by C. W. M. Whitty and O. L. Zangwill. Butterworths: London.

Cole, M., and Perez-Cruet, J. (1964). Prosopagnosia. Neuropsychologia, 2, 237--246.

Critchley, M. (1953). The Parietal Lobes. Arnold: London.

Critchley, M. (1965). Acquired anomalies of colour perception of central origin. Brain, 88, 711-724.

De Busscher, J., Hoffman, G., and Kluyskens, J. (1956). Agnosia visuelle temporaire pour les personnes et opticospatiale pour les objets à la suite d'un ictus unique. Acta Neurologica Belgica, 56, 162-176.

De Renzi, E., and Spinnler, H. (1966). Facial recognition in brain-damaged patients. An experimental approach. Neurology (Minneap.), 16, 145-152.

De Renzi, E., Faglioni, P., and Spinnler, H. (1968). The performance of patients with unilateral brain damage on face recognition tasks. Cortex, 4, 17-34.

Donini, F. (1939). Su di un caso di aprasia costruttiva con grave disorientamento esospaziale e perdita della facolta del viconoscimento della fisonomia della personne. Note Psichiatre, 68, 469-485.

Faust, C. (1955). Die zerebralen Herdstörungen bei Hinterhauptsverletzungen und ihre Beurteilung. Thieme: Stuttgart.

Garland, H., and Pearce, J. (1967). Neurological complications of carbon monoxide poisoning. Quarterly Journal of Medicine, 36, 445-455.

Geschwind, N. (1965). Disconnexion syndromes in animals and man. Part 2. Brain, 88, 585-644.

Gloning, I., Gloning, K., Hoff, H., and Tschabitscher, H. (1966). Zur prosopagnosie. Neuropsychologia, 4, 113-131.

Gloning, I., Gloning, K., Jellinger, K., and Quatember, R. (1970). A case of 'prosopagnosia' with necropsy findings. Neuropsychologia, 8, 199-204.

Gross, C. G. (1974). In press, quoted by Gross et al., 1972.

Gross, C. G., Rocha-Miranda, C. E., and Bender, D. B. (1972). Visual properties of neurons in inferotemporal cortex of the macaque. Journal of Neurophysiology, 35, 96111.

Hécaen, H., and Angelergues, R. (1962). Agnosia for faces (prosopagnosia). Archives of Neurology (Chic.), 7, 92-100.

Hécaen, H., Ajuriaguerra, J. de, Magis, C., and Angelergues, R. (1952). Le problème de l'agnosie des physionomies. Encéphale, 41, 322-355.

Hécaen, H., Angelergues, R., Bernhardt, C., and Chiarelli, J. (1957). Essai de distinction des modalités cliniques de l'agnosie des physionomies. Revue Neurologique, 96, 125144.

Hécaen, H., Penfield, W., Bertrand, W., and Malmo, R. (1956). The syndrome of apractognosia due to lesions of the minor cerebral hemisphere. Archives of Neurology (Chic.), 75, 400-434.

Heidenhain, A. (1927). Beitrag zur Kenntnis der Seelenblindheit. Monatsschrift für Psychiatrie und Neurologie, 66, 61-116.

Hoff, H., and Potzl, O. (1937). Ueber eine optisch-agnostische Störung des 'Physiognomie-Gedachtnisses' (Bezeihungen zur Rückbildung eine Wortblindheit). Zeitschrift für die gesamte Neurologie und Psychiatrie, 159, 367-395.

Hubel, D. H., and Wiesel, T. N. (1962). Receptive fields, binocular interaction and functional architecture in the cat's visual cortex. Journal of Physiology, 160, 106-154. 
Hubel, D. H., and Wiesel, T. N. (1965). Receptive fields and functional architecture in two nonstriate visual areas (18 and 19) of the cat. Journal of Neurophysiology, 28, 229-289.

Hubel, D. H., and Wiesel, T. N. (1968). Receptive fields and functional architecture of monkey striate cortex. Journal of Physiology, 195, 215-243.

Klein, R., and Stack, J. J. (1953). Visual agnosia and alternating dominance; analysis of a case. Journal of Mental Science, 99, 749-762.

Levy, J., Trevarthen, C., and Sperry, R. W. (1972). Perception of bilateral chimeric figures following hemispheric deconnexion. Brain, 95, 61-78.

Lhermitte, F., Chain, F., Escourolle, R., Ducarne, B., and Pillon, B. (1972). Étude anatomoclinique d'un cas de prosopagnosie. Revue Neurologique, 126, 329-346.

Macrae, D., and Trolle, E. (1956). The defect of function in visual agnosia. Brain, 79, 94-110.

Milian, G. (1932). Cécité morphologique. Bulletin de l'Académie de Médecine, 107, 664-666.

Milner, B. (1966). Amnesia following operation on the temporal lobes. In Amnesia, pp. 109-133. Edited by C. W. M. Whitty and O. L. Zangwill. Butterworths: London.

Milner, B. (1968). Visual recognition and recall after right temporal-lobe excision in man. Neuropsychologia, 6, 191209.

Newcombe, F., and Russell, W. R. (1969). Dissociated visual perceptual and spatial deficits in focal lesions of the right hemisphere. Journal of Neurology, Neurosurgery, and Psychiatry, 32, 73-81.
Pallis, C. A. (1955). Impaired identification of faces and places with agnosia for colours. Journal of Neurology, Neurosurgery, and Psychiatry, 18, 218-224.

Pevzner, S., Bornstein, B., and Loewenthal, M. (1962). Prosopagnosia. Journal of Neurology, Neurosurgery, and Psychiatry, 25, 336-338.

Pötzl, O. (1953). Zur Agnosie des Physiognomiegedachtnisses. Wiener Zeitschrift für Nervenheilkunde, 6, 335-354.

Rondot, P. Tzavaras, A., and Garcia, R. (1967). Sur un cas de prosopagnosie persistant depuis quinze ans. Revue Neurologique, 117, 424-428.

Rondot, P., and Tzavaras, A. (1969). La prosopagnosie après vingt années d'études cliniques et neuropsychologiques. Journal de Psychologie Normale et Pathologique, 66, 133166.

Rubens, A. B., and Benson, D. F. (1971). Associative visual agnosia. Archives of Neurology (Chic.), 24, 305-316.

Taylor, A., and Warrington, E. K. (1971). Visual agnosia: a single case report. Cortex, 7, 152-161.

Tzavaras, A., Hécaen, H., and Le Bras, H. (1970). Le problème de la spécificité du déficit de la reconnaissance du visage humain lors des lésions hémisphériques unilatérales. Neuropsychologia, 8, 403-416.

Warrington, E. K., and James, M. (1967). An experimental investigation of facial recognition in patients with unilateral cerebral lesions. Cortex, 3, 317-326.

Wilbrand, H. (1892). Ein Fall von Seelenblindheit und Hemianopsie mit Sectionsbefund. Deutsche Zeitschrift für Nervenheilkunde, 2, 361-387.

Yin, R. K. (1970). Face recognition in brain injured patients : a dissociable ability? Neuropsychologia, 8, 395-402. 